\title{
Raiz tuberosa de yacon (Smallanthus sonchifolius): potencialidade de cultivo, aspectos tecnológicos e nutricionais
}

\author{
Yacon tuberous root (Smallanthus sonchifolius): cultivation potentialities, technological and \\ nutritional aspects
}

\author{
Isabelle Santana ${ }^{\mathrm{I}}$ Marisa Helena Cardoso ${ }^{\mathrm{II}}$
}

\section{- REVISÃo BIBLIOGRÁFICA -}

\section{RESUMO}

O yacon (Smallanthus sonchifolius) é uma planta da família Asteraceae, originária das regiões Andinas. Suas raízes tuberosas são semelhantes a batatas doces em aparência, possuem gosto doce e polpa crocante, sendo bastante consumidas na forma in natura. Seu consumo foi negligenciado até meados dos anos 80, quando foram descobertas peculiaridades em sua composição química que poderiam ser benéficas à saúde humana. A raiz apresenta elevado teor de água, possui reduzido valor energético e, diferentemente da maioria das espécies tuberosas que estocam energia na forma de amido, o yacon tem como principal carboidrato de reserva os frutooligossacarídeos (FOS), os quais têm sido motivo de destaque por exercerem atividade bifidogênica. Esta revisão aborda diferentes aspectos inerentes a esta espécie, como origem histórica, características botânicas, composição química e efeitos pós-colheita.

Palavras-chave: Asteraceae, frutooligossacarídeos, nutracêutico, prebiótico.

\section{ABSTRACT}

Yacon (Smallanthus sonchifolius) is a plant that belongs to Asteraceae family, originated from Andean regions. The tuberous roots produced by this plant are similar to sweet potatoes in appearance, have a sweet taste and a crunch pulp, being often consumed "in natura". Yacon was not usually consumed until the 80's decade, when some peculiarities were discovered in its chemical composition that could be beneficial to human health. The tubers contain high water content, reduced energetic value and, unlikely most tuberous species which store the carbohydrates in the form of starch, yacon has fructooligosaccharides (FOS) as its main reserve carbohydrate, being highlighted by its bifidogenic activity. This paper presents a literature review on many aspects about this specie, such as historical origin, botanical features, chemical composition and post harvest effects.

Key words: Asteraceae, fructooligosaccharides, nutraceutical, prebiotic.

\section{INTRODUÇÃO}

Os problemas inerentes à saúde humana têm sido alvo de discussão por muitos anos e, em conjunto a esses prblemas, também tem-se discutido o potencial protetor da saúde relacionado a alimentos e nutrientes (FREITAS \& JACKIX, 2005). Os mais tradicionais cultivos Andinos, com exceção da batata inglesa e do milho, são praticamente desconhecidos em muitas partes do mundo, apesar destes terem servido por séculos às populações como meio de sobrevivência destas às severas condições climáticas (VALENTOVÁ \& ULRICHOVÁ, 2003).

O yacon é uma raiz tuberosa, oriunda da região Andina, que tem sido considerada como alimento nutracêutico em decorrência de seus componentes designados, como fibras alimentares solúveis e prebióticos - devido a sua baixa digestibilidade pelas enzimas do trato gastrointestinal humano, estímulo seletivo do crescimento e atividade de bactérias intestinais promotoras da saúde (GIBSON \& ROBERFROID, 1995; GUIGOZ et al., 2002). No cultivo desta raiz, também têm sido constatadas vantagens para os produtores e o meio ambiente, além de sua

${ }^{\mathrm{I} C u r s o}$ de Nutrição, Universidade Federal do Estado do Rio de Janeiro (UNIRIO), Rio de Janeiro, RJ, Brasil. Endereço para correspondência: Rua Cosme Velho 415/1007, Cosme Velho, 22241-090, Rio de Janeiro, RJ, Brasil. E-mail: isabellesantana@yahoo.com.br.

IIDepartamento de Tecnologia de Alimentos, Escola de Nutrição, UNIRIO, Rio de Janeiro, RJ, Brasil. 
adaptabilidade a diferentes tipos de condições climáticas. Estas características têm sido vinculadas aos inúmeros benefícios para a população em geral, representando um novo produto a ser explorado e aplicado em níveis social, agrícola, tecnológico e científico.

A presente revisão aborda de maneira ampla a raiz tuberosa yacon (Smallanthus sonchifolius) a fim de identificar aspectos de taxonomia, formas e utilizações do cultivo, características botânicas, composição química, bem como mudanças na composição ocorridas após a colheita.

Taxonomia e generalidades

Yacon é o nome comumente utilizada para designar a planta e a sua raiz de reserva. O yacon representa espécie originária dos Andes, cujo cultivo e consumo datam dos tempos pré-incas (BUTLER \& RIVERA, 2004). Sendo originário dos Andes, região de clima temperado, desenvolve-se desde a Colômbia e a Venezuela até o noroeste da Argentina, em altitudes que variam de 2.000 a 3.400 metros (HERMANN \& FREIRE, 1998).

A planta faz parte da família Asteraceae também denominada de Compositae - e seu nome científico é Smallanthus sonchifolius (Poepp. \& Endl.) H. Robinson. Na literatura científica, também é utilizado Polymnia sonchifolia Poepp. \& Endl. e Polymnia edulis Wedd. para referir-se ao yacon. Segundo GRAU \& REA (1997), o yacon foi classificado originalmente como pertencente ao gênero Polymnia (Compositae, Heliantheae, subtribo Melampodinae), o qual foi criado por Linnaeus em 1751. Na primeira revisão moderna do gênero realizada por Wells (1967), o yacon foi mantido neste gênero e posteriormente uma diferente perspectiva foi adotada por Robinson (1978), quando este determinou que muitas das espécies do gênero Polymnia, entre as quais se encontrava o yacon, na realidade, pertenciam a um gênero que Mackensie havia proposto em 1933: o gênero Smallanthus (SEMINARIO \& VALDERRAMA, 2003). De acordo com GRAU \& REA (1997), existem diferenças importantes entre os gêneros Polymnia e Smallanthus (padrão de estrias na superfície do fruto, ausência de glândulas no apêndice da antera, entre outros). No entanto, apesar de muitos autores referirem-se ao yacon como parte do gênero Polymnia, o ponto de vista de Robinson vem ganhando aceitação.

A taxonomia do yacon é classificada da seguinte maneira: superreino- Eucariontes; reinoPlantae; sub-reino- Embriófita; filo- Tracófita; superclasse- Angiosperma; classe- Dicotiledônea; ordem- Asterales; família- Asteraceae (Compositae); gênero- Smallanthus; espécie- sonchifolius.
A raiz tuberosa tem recebido nomes diferentes nos idiomas andinos dominantes, Aymara e Quéchua. Na língua Quéchua, yacu e unu são palavras que significam água, enquanto yakku significa aquoso ou insípido. Aricoma e aricuma, os termos Aymara, são utilizados em certas áreas da Bolívia. Llaqon, llacum, llacuma ou yacumpi representam as palavras Quéchua para designar o yacon. No Equador, jicama, chicama, shicama, jiquima ou jiquimilla são os nomes populares das espécies. O termo arboloco, utilizado na Colômbia, sugere uma descendência hispânica. $O$ yacon também recebeu nomes em idiomas europeus, criados provavelmente por pesquisadores ou cultivadores locais: poire de terre (França), yacon strawberry (Estados Unidos), leafcup e yacón (Inglaterra), polimnia (Itália). De maneira geral o termo yacon é o mais utilizado, principalmente em países como Colômbia, Peru, Argentina, países europeus, Japão, Nova Zelândia e Brasil (GRAU \& REA, 1997).

A maior parte do yacon é cultivado nos Andes, em parcelas ou lotes familiares, que o utilizam para o próprio consumo, a comercialização em feiras rurais ou em parcelas comerciais que não ultrapassam um hectare de cultivo, representando uma importante alternativa nutricional e econômica para a agricultura de subsistência e ocupando o lugar de frutas e vegetais na dieta de pequenas comunidades. Esta raiz mostra ser uma fonte alimentar aquosa para que os camponeses que trabalham nas lavouras possam se refrescar. Entretanto, justamente pela ligação desta característica ao fato de ser um alimento de baixo valor calórico, o seu uso foi negligenciado por muitos anos, uma vez que não representava um alimento que fornecesse energia suficiente para o trabalho árduo realizado nas frias regiões Andinas. Dessa forma o cultivo de yacon não se destacou nos sistemas agrícolas sul-americanos, em que se priorizou o cultivo da batata e do milho, culturas essenciais para a sobrevivência da população (GRAU et al., 2001). Em nível urbano, a falta de demanda para esta raiz poderia abranger algumas razões como a curta vida de prateleira, a falta de familiaridade do consumidor com este alimento (HERMANN \& FREIRE, 1998), os problemas de colheita, o armazenamento, a sazonalidade e os fatores bióticos que envolvem esta espécie silvestre.

$\mathrm{O}$ reconhecimento recente dos efeitos promissórios para a saúde advindos do consumo de yacon aumentou o interesse comercial nos mercados das cidades, levando ao desenvolvimento de atividades comerciais em torno de seu cultivo (MANRIQUE \& PÁRRAGA, 2005).

Nas últimas três décadas, o cultivo de yacon tem se estendido para outros continentes e, na 
atualidade, o yacon já é cultivado em muitos países fora dos Andes, como Paraguai, Estados Unidos, Eslováquia, China, Coréia e Taiwan (LACHMAN et al., 2004). A rota migratória que a planta seguiu foi plenamente identificada. Na década de 80 , o yacon saiu pela primeira vez do Equador até a Nova Zelândia, país em que se adaptou bem e onde hoje é cultivado em pequena escala (MANRIQUE \& HERMANN, 2004). Em 1985, ele foi levado da Nova Zelândia ao Japão, país onde tem se realizado a maior quantidade de investigações científicas referentes ao manejo agronômico, à composição química, às propriedades sobre a saúde e desenvolvimento de produtos processados (LACHMAN et al., 2004). O Japão foi o centro da dispersão da raiz até outros países, como Coréia e Brasil (SEMINARIO \& VALDERRAMA, 2003).

O yacon foi introduzido no Brasil no início dos anos 90 (MOSCATTO et al., 2004), onde o consumo expressivo iniciou-se em meados dos anos 2000 e a raiz tornou-se conhecida popularmente como batata yacon ou batata "diet".

\section{Aspectos botânicos}

A planta apresenta sistema subterrâneo complexo, não havendo consenso sobre a denominação dos órgãos que o compõem. Logo, encontram-se referências de que seja tubérculo, caule rizomatoso (NATIONAL RESEARCH COUNCIL, 1989), rizoma simpodial (GRAU \& REA, 1997), raiz tuberosa, raiz comestível e tuberosa, ou, rizoma lenhoso, rizoma carnoso e raiz de reserva (MACHADO et al., 2004). Em botânica, denomina-se raiz tuberosa o tipo de raiz subterrânea muito espessa que acumula substâncias de reserva, sendo incluídos nessa categoria hortaliças como: cenoura, nabo, rabanete, mandioca, dália, batata doce e beterraba (BOTÂNICA, 2006). O tubérculo também atua como órgão de reserva de energia para a planta, entretanto, ele representa um engrossamento do caule que algumas plantas desenvolvem abaixo da superfície do solo, a exemplo da batata inglesa (DICIONÁRIO DE BOTÂNICA, 2006).

Embora alguns aspectos agronômicos e bioquímicos do yacon sejam relativamente conhecidos, pouco se sabe a respeito da morfologia e da natureza do sistema subterrâneo. A partir desta prerrogativa, foi realizado estudo por MACHADO et al. (2004) a fim de caracterizar botanicamente a morfoanatomia do sistema subterrâneo pelo qual o yacon é composto. Foi definido que "a planta apresenta eixos aéreos, com folhas e gemas vegetativas e florais, e um sistema subterrâneo espessado de natureza mista representado por rizóforos e raízes. Todo o sistema radicular é formado por raízes adventícias, sendo que algumas permanecem delgadas e outras sofrem intensa tuberificação".

Em vista desse resultado, “com relação às diversas denominações atribuídas ao órgão espessado e comestível, principal fonte de frutanos de Smallanthus sonchifolius, justifica-se apenas a utilização de raiz tuberosa", uma vez que o estudo anatômico evidenciou que a organização do sistema vascular deste órgão é típica de raiz. As referências na literatura para tubérculo e rizoma não são adequadas, em virtude destes serem órgãos subterrâneos de natureza caulinar (MACHADO et al., 2004). Esta elucidação serve também para exemplificar outros tubérculos com os quais o yacon é comumente confundido, a exemplo da difusão popular do termo "batata yacon" onde a raiz é comparada à batata inglesa (Solanum tuberosum) em questão de nomenclatura. Outro motivo de equívoco é a semelhança da aparência do yacon com a batata doce (Ipomoea batatas). Apesar de ser uma raiz, a batata doce armazena amido como principal carboidrato (LEONEL et al., 1998), diferentemente do yacon.

O sistema subterrâneo é constituído por três partes: os rizomas ou rizóforos, as raízes fibrosas ou delgadas e as raízes reservantes ou tuberosas. Os rizóforos ou rizomas são ricos em fibras duras e não digeríveis e contêm gemas que dão origem a novas plantas. As raízes fibrosas são muito delgadas e sua função é a fixação da planta ao solo e a absorção de água e nutrientes. As raízes de reserva - a parte comestível propriamente dita - são engrossadas, de formato principalmente fusiforme (GRAU \& REA, 1997), com polpa de cor branca, creme ou púrpura. O peso das raízes de reserva pode variar de 50 a 1000 gramas, porém, mais comumente varia entre 300 e 600 gramas. Uma planta produz em média entre 2 e $4 \mathrm{~kg}$ de raízes de reserva (SEMINARIO \& VALDERRAMA, 2003).

\section{O cultivo}

O yacon é uma planta perene e herbácea que mede entre um e 2,5 metros de altura (SEMINARIO $\&$ VALDERRAMA, 2003). A planta é rústica e resiste bem à seca. Apesar de sua origem andina, o yacon representa uma espécie com desenvolvimento extremamente adaptável quanto ao clima, à altitude e aos tipos de solo, sendo cultivada com sucesso mesmo em países de clima quente como o Brasil. A maturidade fisiológica da planta é alcançada entre 6 e 10 meses após o plantio, quando as flores começam a desabrochar, sendo que este fator depende da zona onde a planta é cultivada. Em altitudes mais baixas, a maturidade é adiantada. Este estágio será, então, seguido por um período de incremento do conteúdo dos oligofrutanos nos rizóforos e nas raízes tuberosas, passando para uma fase de senescência da parte aérea e dormência das partes subterrâneas (NATIONAL

Ciência Rural, v.38, n.3, mai-jun, 2008. 
RESEARCH COUNCIL, 1989). A colheita das raízes tuberosas para consumo é realizada por volta de $10 \mathrm{e}$ 12 meses após o plantio, quando a parte aérea está totalmente seca (OLIVEIRA \& NISHIMOTO, 2004).

O yacon possui em suas folhas dois sistemas de defesa: uma trama de pêlos que dificulta o acesso dos insetos e uma alta densidade de glândulas. A associação destes mecanismos faz com que as folhas de yacon sofram menos ataques por insetos, permitindo seu cultivo sem a utilização de agrotóxicos, gerando dessa forma, menor contaminação do produto (GRAU et al., 2001).

Algumas das vantagens do cultivo de yacon para os produtores e o meio ambiente foram apontadas por GRAU \& REA (1997). Segundo os autores, o yacon apresenta alta produtividade, é adaptável a uma extensa gama de climas e solos, permite controle da erosão, apresenta potencial uso como forrageira (tanto as partes subterrâneas quanto as aéreas), é passível de extensa variedade de processamentos alternativos e apresenta boa durabilidade pós-colheita se armazenado adequadamente.

\section{A raiz tuberosa}

A raiz tuberosa produzida pela planta possui sabor semelhante ao de frutas como o melão, com polpa levemente amarelada, crocante e aquosa (VALENTOVÁ \& ULRICHOVÁ, 2003; MANRIQUE \& HERMANN, 2004). Quando colhidas, as raízes tendem a apresentar sabor amiláceo, motivo pelo qual são expostas à luz solar por muitos dias após a colheita a fim de incrementar seu gosto doce, técnica conhecida como soleado (GRAEFE et al., 2004). As raízes são consumidas geralmente cruas e descascadas, uma vez que a casca possui sabor resinoso (GRAU \& REA, 1997). Outras formas de consumo compreendem a cocção a vapor, em água, ou em fritura. Nos mercados locais andinos, o yacon é classificado como fruta e é exposto juntamente com as maçãs, os abacates e os abacaxis, em vez de serem colocados com as batatas e outras culturas de tubérculos e raízes (VALENTOVÁ \& ULRICHOVÁ, 2003).

Apesar da forma mais comum de se consumir yacon ser a in natura, muitos produtos como xarope, suco, chips (yacon cortado em lâminas desidratado) e chá (das folhas) têm sido desenvolvidos a fim de aproveitar as potencialidades desse alimento (MANRIQUE \& HERMANN, 2004). No Japão, as raízes tuberosas são transformadas em produtos de panificação, bebidas fermentadas, pó ou polpa liofilizada, picles entre outros (GRAU \& REA, 1997; VALENTOVÁ \& ULRICHOVÁ, 2003). Uma vez que os frutooligossacarídeos são açúcares não-redutores, eles apresentam a vantagem de não serem susceptíveis à reação de Maillard. Quanto à estabilidade, estes compostos são estáveis a valores de $\mathrm{pH}$ superiores a 3 e temperaturas de até $140^{\circ} \mathrm{C}$. Desse modo, os FOS não são degradados na maioria dos processos térmicos das indústrias de alimentos (MOURA, 2004).

Mesmo que o yacon seja um alimento, esporadicamente seu uso é reportado para fins medicinais. Em certas regiões peruanas, ele é considerado antirraquítico. $\mathrm{Na}$ medicina folclórica andina, as raízes são consideradas elementos frescos e empregadas desde épocas muito antigas como remédio para afecções renais e hepáticas. Na Bolívia, a raiz é consumida por pessoas com diabetes e com problemas digestivos. Os camponeses andinos também o consideram um rejuvenescedor da pele (SEMINARIO \& VALDERRAMA, 2003)

\section{Composição química}

O yacon tem sido alvo de atenção nas últimas décadas visto que ele apresenta compostos bioativos de importância à saúde humana (RIVERA \& MANRIQUE, 2005). Sua composição tem como principais substâncias água e carboidratos, os quais são armazenados principalmente sob forma de frutooligossacarídeos (FOS), entre outros açúcares livres.

O percentual de água das raízes situa-se em torno de 83 a $90 \%$ do peso fresco. Devido ao alto conteúdo de água, o valor energético da raiz é baixo (LACHMAN et al., 2004). Este fator também reduz sua vida útil em condições ambientais - aproximadamente 7 dias - visto que os tecidos internos das raízes se apresentam muito delicados, característica que os predispõem a sofrer rachaduras ou a romperem-se facilmente durante a colheita, a embalagem e o transporte (MANRIQUE \& PÁRRAGA, 2005).

Em relação aos carboidratos, entre os açúcares encontrados estão os monossacarídeos frutose e glicose, e os oligossacarídeos sacarose e frutooligossacarídeos, além de traços de amido e inulina (GRAU \& REA, 1997). As raízes contêm entre 10 e 14\% de matéria seca, sendo esta composta por aproximadamente $90 \%$ de carboidratos (MANRIQUE \& PÁRRAGA, 2005). A composição dos açúcares varia de forma significante em função de fatores como a cultivar, a época de cultivo e a colheita, o tempo e a temperatura na pós-colheita (SEMINARIO\& VALDERRAMA, 2003).

Diferentemente da maioria de tubérculos e raízes que armazenam carboidratos na forma de amido, o yacon armazena essencialmente frutooligossacarídeos (FOS), açúcares que não podem ser digeridos diretamente pelo organismo humano devido à ausência de enzimas necessárias para o metabolismo destes elementos e são considerados compostos bioativos na alimentação humana (CASTILLOALFARO \& VIDAL MELGAREJO, 2005). Existe uma confusão de termos quando se faz referência 
ao tipo de carboidrato predominante nas raízes de yacon. Em diversos artigos da literatura, é mencionado que as raízes de yacon contêm inulina como componente principal. Apesar de muitas referências científicas citarem esse tipo de informação, esta não é exata, visto que estritamente falando, o yacon contém apenas frutooligossacarídeos. A diferença entre FOS e inulina reside no número de moléculas de frutose que têm estas cadeias. Na inulina, este número varia entre 2 e 60, enquanto que nos FOS, que apresentam cadeias menores, o número varia entre 2 e 10 . Isto significa que os FOS podem ser considerados como um subgrupo da inulina, motivo pelo qual alguns autores preferem empregar o termo frutooligossacarídeos do tipo inulina para referir-se com maior precisão à natureza destes açúcares (SEMINARIO \& VALDERRAMA, 2003). Mesmo que a proporção de cada açúcar possa variar, pode-se considerar a seguinte composição em base seca: 40 a $70 \%$ de FOS, 5 a $15 \%$ de sacarose, 5 a $15 \%$ de frutose e menos de $5 \%$ de glicose (MANRIQUE \& PÁRRAGA, 2005).

O conteúdo de proteínas, lipídios, vitaminas e minerais das raízes é bastante baixo (SEMINARIO \& VALDERRAMA, 2003). O mineral mais abundante é o potássio, que existe em quantidades significativas e

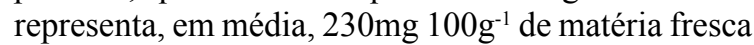
comestível ou de 1 a $2 \%$ do peso seco. Em menores quantidades são encontrados o cálcio, fósforo, magnésio, sódio, ferro, zinco, manganês e cobre (MANRIQUE \& PÁRRAGA, 2005). Algumas vitaminas encontradas no yacon geralmente representam elementos traço na composição, exceto o ácido ascórbico. Entre elas estão: retinol, caroteno, tiamina, riboflavina e niacina. Outro composto noticiado foi o triptofano, existente em quantidades médias de 14,6 \pm 7,1 $\mu \mathrm{g} \mathrm{g}^{-1}$ (TAKENAKA et al., 2003; VALENTOVÁ \& ULRICHOVÁ, 2003).

Confirmou-se a presença de compostos fenólicos (SIMONOVSKA et al., 2003) como ácido clorogênico (éster de ácido caféico e ácido quínico GUTIÉRREZ MAYDATA, 2002), ácido ferúlico e ácido caféico, tanto nas folhas como nas raízes tuberosas de yacon. TAKENAKA et al. (2003) identificaram cinco derivados do ácido caféico em raízes de yacon, sendo que dois destes compreendiam o ácido clorogênico (ácido 3-cafeoilquínico) e ácido 3,5-dicafeoilquínico. Três eram representados por ésteres do ácido caféico e altrárico: ácido 2,4 ou 3,5-dicafeoilaltrárico; ácido 2,5dicafeoilaltrárico; ácido 2,3,5 ou 2,4,5-tricafeoilaltrárico. VALENTOVÁ \& ULRICHOVÁ (2003) identificaram, além dos compostos fenólicos citados, quercetina e outros dois flavonóides. Em comparação a outras raízes e tubérculos, as raízes do yacon possuem elevada quantidade de compostos fenólicos, cerca de $200 \mathrm{mg}$ $100 \mathrm{~g}^{-1}$ de matéria fresca comestível, sendo o ácido clorogênico presente em 48,5 $\pm 12,9 \mu \mathrm{g} \quad \mathrm{g}^{-1}$ de polpa fresca (VALENTOVÁ\& ULRICHOVÁ, 2003). De acordo com GUTIÉRREZ MAYDATA(2002), algumas bebidas consumidas habitualmente se apresentam ricas em compostos fenólicos, como, por exemplo: o café (200$500 \mathrm{mg}$ por xícara), o chá (150-200mg por xícara) e o vinho tinto (200-800mg por taça).

Ainda que a concentração de compostos fenólicos nas raízes seja alta, a concentração se apresenta ainda mais elevada em outros órgãos da planta, como as folhas e a cepa. Esses compostos têm como propriedades gerais: serem antioxidantes, exercer efeitos quelantes e modular à atividade de vários sistemas enzimáticos, de modo a atuar majoritariamente na dieta como elementos que promovem saúde ante fatores químicos e físicos estressantes para o organismo (GUTIÉRREZ MAYDATA, 2002).

O yacon tem sido reportado como uma boa fonte da enzima fenol oxidase, a qual catalisa a oxigenação de compostos fenólicos a quinonas que, após polimerização, apresentam os típicos pigmentos marrons ou pretos, conhecidos da oxidação enzimática de frutas e vegetais (VALENTOVÁ \& ULRICHOVÁ, 2003). Segundo BUTLER \& RIVERA (2004), é importante considerar a subcamada da casca quando se estuda o processo de descascamento de yacon, pois é nesta parte da raiz que se concentram os taninos e os polifenóis. Durante o descascamento e o processamento do yacon, quando as membranas das células são rompidas, os polifenóis e os taninos estão disponíveis para se misturar aos outros componentes, especialmente as enzimas citoplasmáticas, o que pode ocasionar um processo conhecido como oxidação enzimática, e a epiderme torna-se rapidamente escura quando exposta ao ar (VALENTOVÁ \& ULRICHOVÁ, 2003). Esta oxidação se dá em presença de oxigênio livre, escurecendo rapidamente a superfície recémcortada das raízes tuberosas de yacon, prejudicando sua aparência e a de seus produtos. Do ponto de vista prático, o controle do escurecimento enzimático é geralmente limitado à inibição da enzima, pois inativase as enzimas polifenoloxidase e peroxidase, responsáveis pela reação de escurecimento (CABELLO, 2005). Entre os métodos propostos para a prevenção da oxidação, estão: a desidratação, o armazenamento a baixas temperaturas, o tratamento térmico, a utilização de antioxidantes, a eliminação do oxigênio do meio, entre outros (LUPETTI et al., 2005). Em experimento de RIVERA \& MANRIQUE (2005) para processamento de sumo de yacon, foram utilizados $1,3 \mathrm{~g}$ de ácido ascórbico para cada quilograma de extrato de raízes descascadas passadas por centrífuga a fim de controlar o escurecimento da amostra. 
Efeitos pós-colheita

Nos primeiros dias de desenvolvimento das raízes tuberosas de yacon, a concentração de açúcares simples nestas é muito alta e a de FOS é muito baixa. No decorrer dos dias, intervêm duas enzimas que são as responsáveis pela síntese de FOS a sacarose: sacarose frutosiltransferase (SST), a qual catalisa a união de duas moléculas de sacarose para produzir o trissacarídeo 1-cestose (ou 1-Kestose) - o frutooligossacarídeo mais simples que existe e que serve de intermediário para a síntese de FOS de maior grau de polimerização - mais uma glicose livre. A segunda enzima é a frutano: frutano frutosiltranferase (FFT) e sua função é catalisar a união de dois oligofrutanos para produzir outro de maior grau de polimerização, o que ocorre com a transferência de terminais frutosil de outras moléculas de frutanos para a 1-cestose, promovendo a polimerização da cadeia. A enzima FFT pode também transferir resíduos de frutose da cadeia de frutanos para a sacarose, iniciando a formação de novas cadeias (VIJN \& SMEEKENS, 1999; SEMINARIO \& VALDERRAMA, 2003).

Uma vez retirados os órgãos das plantas durante a colheita, eles se tornam unidades independentes e logo transformações químicas e bioquímicas assumem um papel de elevada importância na produção de energia para os processos de respiração e transpiração. Desse modo, a energia necessária para suprir a demanda destes processos provém da despolimerização das cadeias dos frutooligossacarídeos armazenados (CARVALHO et al., 2004).

Diferentes estudos têm demonstrado que logo após a colheita é iniciado, nas raízes, um rápido processo de mudança na composição química de seus açúcares: os açúcares polimerizados tendem a se despolimerizar com o tempo pós-colheita, isto é, os FOS são hidrolisados em açúcares simples pela ação da enzima frutano hidrolase (FH), que os converte em frutose, sacarose e glicose. Após uma semana de armazenamento à temperatura ambiente, cerca de $30 \mathrm{a}$ $40 \%$ dos FOS terão sido transformados em açúcares simples (GRAEFE et al., 2004). No entanto, a velocidade desta conversão é mais lenta se o yacon é armazenado em temperaturas de refrigeração. As temperaturas de refrigeração são úteis também para reduzir a taxa de putrefação e deterioração das raízes durante o armazenamento (MANRIQUE \& PÁRRAGA, 2005).

O processo de degradação dos frutanos ocorre por despolimerização da cadeia, em que atua primeiramente a enzima frutano hidrolase $(\mathrm{FH})$, rompendo a cadeia entre os resíduos de frutose até a molécula terminal de sacarose. Em seguida, a invertase rompe a molécula de sacarose resultando frutose e glicose livre (CARVALHO et al., 2004). Por meio deste sistema multienzimático ocorre a síntese e a degradação de todos os tipos de FOS que existem nas raízes tuberosas de yacon (SEMINARIO \& VALDERRAMA, 2003; CARVALHO et al., 2004).

A hidrólise de FOS em açúcares simples (glicose, frutose e sacarose) pode ser importante para a comercialização do yacon. O soleado é uma prática tradicional e provavelmente as raízes se tornam mais adocicadas devido à desidratação (há perda de aproximadamente $40 \%$ de seu peso fresco) e de uma parte importante dos FOS que se convertem em açúcares simples. Isso sugere que, para obter o máximo de benefício dos FOS, a melhor forma de consumir yacon seria a recém colhida. GRAEFE et al. (2004) determinaram que a concentração de FOS nas raízes soleadas é a mesma que nas raízes frescas. Isso ocorre devido ao fato de que a proporção de FOS que se converte em açúcares simples é compensada pela desidratação das raízes. Isso significa que uma pessoa consumiria a mesma quantidade de FOS tanto em $100 \mathrm{~g}$ de yacon soleado como em $100 \mathrm{~g}$ de yacon fresco.

Foram investigadas as mudanças nos conteúdos de frutose, glicose, sacarose e oligofrutanos durante o crescimento e o armazenamento das raízes tuberosas de yacon (ASAMI et al., 1991). Relatou-se que o conteúdo de FOS em raízes armazenadas a uma temperatura de $5^{\circ} \mathrm{C}$ foi significativamente maior ao de raízes armazenadas a $25^{\circ} \mathrm{C}$, o que sugere que a velocidade de conversão se torna mais lenta quando as raízes são armazenadas em temperatura de refrigeração (SEMINARIO \& VALDERRAMA, 2003). Durante duas semanas de armazenamento das raízes tuberosas de yacon em buracos cavados na terra a $5^{\circ} \mathrm{C}$ e $25^{\circ} \mathrm{C}$, os conteúdos de frutooligossacarídeos diminuíram respectivamente para 21,33 e $41 \%$ do total determinado na colheita. Coincidentemente o conteúdo de frutose, glicose e sacarose aumentou.

Considerável diminuição de FOS na matéria seca de raízes tuberosas de yacon ocorreu em apenas alguns dias em experimento conduzido por GRAEFE et al. (2004), resultando em grandes quantidades de açúcares simples originados da despolimerização dos FOS. Durante doze dias de armazenamento a concentração de FOS, que representava $50-62 \%$ da matéria seca no início do experimento, diminuiu em cerca de um terço em todos os cultivares após o armazenamento (GRAEFE et al., 2004). Durante a exposição solar, o maior decréscimo da concentração de FOS em matéria seca da raiz, bem como a maior desidratação ocorreram durante os primeiros dois dias. Essa rápida conversão inicial dos FOS aconteceu provavelmente devido ao aumento da temperatura induzido pela radiação solar, favorecendo a atividade enzimática dentro de um curto período de tempo. Foi 
constatada uma maior diminuição dos FOS nas raízes armazenadas em altitudes mais baixas, o que é atribuído às maiores temperaturas durante o dia e a noite, as quais favorecem a atividade enzimática (GRAEFE et al., 2004). Após duas semanas de armazenamento, as taxas de conversão começaram a estabilizar. A menor taxa de degradação dos FOS, que ocorreu após os dois primeiros dias de exposição solar, pode ser conseqüência da rápida desidratação das raízes, o que pode ter levado a uma atividade reduzida das enzimas responsáveis pela despolimerização dos FOS.

Devido à ocorrência da despolimerização dos frutanos acumulados após a colheita, é de grande importância estabelecer manejo pós-colheita que busque minimizar as alterações no conteúdo e na distribuição destes carboidratos a fim de prolongar a vida útil destes produtos (VILHENA, 2001; SEMINARIO \& VALDERRAMA, 2003). GRAEFE et al. (2004) estudaram a variação do FOS em yacon póscolheita que foi seca durante seis dias ao sol. Foi verificado que, para o consumo do yacon sem ser direcionado para fins dietéticos, esta é uma tecnologia apropriada. Entretanto, se produtos com o maior conteúdo possível de oligofrutanos são requeridos, as raízes necessitam ser imediatamente processadas após a colheita ou então refrigeradas (MANRIQUE \& HERMANN, 2004) para que haja uma maior conservação e estabilização dos oligofrutanos.

As raízes do yacon são bastante suscetíveis à desidratação quando expostas diretamente ao sol. Como conseqüência da desidratação, as raízes perdem peso e adquirem uma aparência rugosa que as deixa menos atrativas para o consumidor. O mais recomendável para evitar uma desidratação rápida é realizar a colheita das raízes e colocá-las imediatamente em local escuro, seco e fresco (GRAU \& REA, 1997). No caso de não serem comercializadas logo após a colheita e somente armazenadas por um período curto de tempo, é preferível que as raízes sejam embaladas ainda sujas de terra, uma vez que esta ação pode ajudar a tornar a desidratação mais lenta e causar menor dano à casca da raiz durante o transporte (SEMINARIO \& VALDERRAMA, 2003).

\section{CONCLUSÃO}

Atualmente, o yacon é comercializado como nutracêutico e tem sido descrito como o alimento com maior conteúdo de FOS na natureza. A atividade prebiótica dos FOS contidos no yacon tem sido associada a efeitos favoráveis à saúde como alívio da constipação, aumento na absorção de minerais, fortalecimento do sistema imunológico, diminuição do desenvolvimento de câncer de cólon, os quais são cientificamente comprovados quando os FOS são consumidos em dosagens recomendadas. Além desse fator, a raiz contribui com doses razoáveis de minerais, como o potássio, além de compostos fenólicos para a alimentação humana. Há evidências de que a utilização de FOS na alimentação animal também pode atuar no controle da disseminação de doenças através do aprimoramento do sistema imunológico, como, por exemplo, em frangos criados sem administração de antibióticos, área esta que requer mais estudos a fim de se comprovar a eficácia e a segurança desses compostos.

Apesar dos notórios benefícios provenientes do cultivo do yacon tanto para obtenção das raízes e desenvolvimento de produtos quanto para o solo, as áreas onde a planta é cultivada no Brasil geralmente se restringem ao Estado de São Paulo. Logo, são requeridas mais pesquisas e divulgação a respeito das potencialidades da espécie para o plantio em diferentes tipos de condições climáticas. Igualmente são necessárias implementações de técnicas e processamentos para que a raiz - no pós-colheita - e seus produtos contenham maiores teores de componentes como os FOS e os polifenóis, bem como apresentem características que tornem o consumo mais atrativo e popular, posto que é um alimento promissor.

\section{REFERÊNCIAS}

ASAMI, T. et al. Fluctuations of oligofructan contents in tuber of yacon (Polymnia sonchifolia) during growth and storage. Japanase Society of Soil Science Plant Nutrition, Tokio, v.62, p.621-627, 1991.

BOTÂNICA. Capturado em 5 abr. 2006. Online. Disponível na internet http://www.aultimaarcadenoe.com/biologia 7o.htm.

BUTLER, G.; RIVERA, D. Innovations in peeling technology for yacon. Project Report International Potato Center, 2004. Capturado em 13 fev. 2006. Online. Disponível na internet http://www.cipotato.org/artc/CIPcrops/20041127.pdf.

CABELLO, C. Extração e pré-tratamento químico de frutanos de yacon, Polymnia sonchifolia. Ciência e Tecnologia de Alimentos, Campinas, v.25, n.2, p.202-207, 2005.

CARVALHO, S. et al. Fructanos en raices tuberosas de yacon (Smallanthus sonchifolius Poep. \& Endl.) expuestas al sol y almacenadas bajo condiciones ambientales. Agro-Ciencia, Botucatu, São Paulo, v.20, n.1, p.17-23, 2004.

CASTILlO ALFARO, M.E.; VIDAL MELGAREJO, S.A. El yacón: una nueva alternativa en la prevención y el tratamiento de la salud. 2005. Capturado em 2 ago. 2005. Online. Disponível na Internet http://infoagro.net/es/apps/news/ record_view.cfm?vsys $=\mathrm{a} 5 \& \mathrm{id}=8641$.

DICIONÁRIO DE BOTÂNICA. Capturado em 5 abr. 2006. Online. Disponível na Internet http://www.gestialba.com/public/ botanico/botancastt01.htm. 
FREITAS, D.G.C.; JACKIX, M.N.H. Efeito de bebida adicionada de frutoligossacarídeo e pectina no nível de colesterol e estimulação de bifidobactérias em hamsters hipercolesterolêmicos. Brazilian Journal of Food Technology, Campinas, v.8, n.1, p.81-86, 2005.

GIBSON, G.R.; ROBERFROID, M.B. Dietary modulation of the human colonic microbiota: introducing the concept of prebiotics. Journal of Nutrition, Madison, v.125, n.6, p.14011412, 1995.

GRAEFE et al. Effects of post-harvest treatments on the carbohydrate composition of yacon roots in the Peruvian Andes. Field Crops Research, Lima, v.86, p.157-165, 2004.

GRAU, A. et al. El retorno del yacon. Ciencia Hoy, v.11, n.63, 2001. Capturado em 20 jan. 2006 . Online. Disponível na Internet http://www.cienciahoy.org/hoy63/yacon2.htm.

GRAU, A; REA, J. Yacon. Smallanthus sonchifolius (Poep. \& Endl.) H. Robinson. In: HERMANN, M.; HELLER, J. (Eds.) Andean roots and tubers: ahipa, arracacha, maca and yacon. Promoting the conservation and use of underutilized and neglected crops. (Institute of Plant Genetics and Crop Plant Research). Gatersieben/International Plant Genetic Resources Institute. Rome, Italy, 1997. p.199 242. Capturado em 4 nov. 2005. Online. Disponível na Internet http://www.cipotato.org/market/ARTChermann/yacon.pdf.

GUIGOZ, Y. et al. Effects of oligosaccharides on the fecal flora and non-specific immune system in elderly people. Nutrition of Research, Tarrytown, v.22, p.13-25, 2002.

GUTIÉRREZ MAYDATA, A. Café, antioxidantes y proteción a la salud. Medisan, Santa Clara, v.6, n.4, p.72-81, 2002.

HERMANN, M.; FREIRE, I. Compositional diversity of the yacon storage root. In: . Impact on a changing world. Lima: Centro Internacional de la Papa, 1998. p.199-242.

LACHAN, L. et al. Saccharides of yacon [Smallanthus sonchifolius (Poepp. et Endl.) H. Robinson] tubers and rhizomes and factors affecting their content. Plant soil environment, Czech Republic, v.50, n.9, p.383-390, 2004.

LEONEL, M. et al. Processamento industrial de fécula de mandioca e batata doce - um estudo de caso. Ciência e Tecnologia de Alimentos, Campinas, v.18, n.3., p.343345, 1998.

LUPETTI, K.O. et al. Análise de imagem em química analítica: empregando metodologias simples e didáticas para entender e prevenir o escurecimento de tecidos vegetais. Química Nova, São Carlos, v.28, n.3, p.548-554, 2005.

MACHADO, S.R. et al. Morfoanatomia do sistema subterrâneo de Smallanthus sonchifolius (Poepp. \& Endl.) H. Robinson (Asteraceae). Revista Brasileira Botânica, Botucatu, v.27, n. 1, p.115-123, 2004.

MANRIQUE, I.; HERMANN, M. Yacon - Fact Sheet. Lima, Peru: International Potato Center (CIP), 2004. Capturado em 22 dez. 2005. Online. Disponível na Internet www.cipotato.org/ artc/cipcrops/factsheetyacon.pdf.

MANRIQUE, I.; PÁRRAGA, A. Conservación y uso de la biodiversidad de raíces y tubérculos Andinos: Una década de investigación para el desarrollo (1993-2003). Jarabe de yacón: principios y procesamiento. Lima: Centro Internacional de La Papa, 2005. 40p.

MOSCATTO, J.A. et al. Farinha de yacon e inulina como ingredientes na formulação de bolo de chocolate. Ciência Tecnologia Alimentos, Campinas, v.24, n.4, p.634-640, 2004.

MOURA, C.P. Aplicação de redes neuronais para a predição e otimização do processo de secagem de yacon (Polymnia sonchifolia) com pré-tratamento osmótico. 2004. 115f. Dissertação (Mestrado em Tecnologia de Alimentos) Universidade Federal do Paraná, Curitiba.

NATIONAL RESEARCH COUNCIL. Lost crop of the Incas: Little Known Plants of the Andes with Promise for Worldwide Cultivation (1989). Capturado em 15 mar. 2006. Online. Disponível na Internet http://www.nap.edu/openbook/ 030904264X/html/115.html.

OLIVEIRA, M.A.; NISHIMOTO, E.K. Avaliação do desenvolvimento de plantas de yacon (Polymnia sonchifolia) e caracterização dos carboidratos de reservas em HPLC. Brazilian Journal of Food Technology, Campinas, v.7, n.2, p.215-220, 2004

RIVERA, D.; MANRIQUE, I. Zumo de Yacón - Ficha Técnica. Centro Internacional de la Papa (CIP). Lima, Peru, 2005. Capturado em 9 jan. 2006. Online. Disponível na Internet www.cipotato.org/artc/cipcrops/fichazumoyacon.pdf.

SEMINARIO, J.; VALDERRAMA, M. El yacon: fundamentos para el aprovechamiento de un recurso promisorio. Lima, Peru: Centro Internacional de la Papa (CIP), Universidad Nacional de Cajamarca, Agencia Suiza para el Desarrollo y la Cooperación (COSUDE), 2003. 60p. Capturado em 20 nov. 2005. Online. Disponível na Internet h t t p : / / w w w c i potato.org/market/P D F docs/ Yacon_Fundamentos_password.pdf.

SIMONOVSKA, B. et al. Investigation of phenolic acids in yacon (Smallanthus sonchifolius) leaves and tubers. Journal of Chromatography A, Czech Republic, v.1016, n.1, p.89-98, 2003.

TAKENAKA, M. Caffeic acid derivatives in the roots of yacon (Smallanthus sonchifolius). Journal of Agricultural and Food Chemistry, Japan, v.51, n.3, p.793-796, 2003.

VALENTOVÁ, K.; ULRICHOVÁ, J. Smallanthus sonchifolius and Lepidium meyenii - prospective Andean crops for the prevention of chronic diseases. Biomedical Papers, Czech Republic, v.147, n.2, p.119-130, 2003.

VIJN, I.; SMEEKENS, S. Fructan: more than a reserve carbohydrate? Plant Physiology, v.120, p.351-359, 1999.

VILHENA, S.M.C. Ciclo de cultivo e técnicas pós-colheita de yacon (Polymnia sonchifolia Poep. Endl.) em função do conteúdo de frutose total nos órgãos subterrâneos. 2001. 73f. Tese (Doutorado em Agronomia) - Universidade Estadual de São Paulo, Botucatu. 